\title{
Sepia Ink Oligopeptide Induces Apoptosis of Lung Cancer Cells via Mitochondrial Pathway
}

\author{
Xiaohua Wang ${ }^{\mathrm{a}}$ Cheng Chen ${ }^{\mathrm{b}} \quad$ Guoren Zhou $^{\mathrm{a}}$ Jinjun Ye ${ }^{\mathrm{b}}$ Rong Yin ${ }^{\mathrm{c}}$ \\ Dongjie Feng ${ }^{c}$ Shuai Zhang ${ }^{c}$ Xiaojun Wang ${ }^{c}$ Xin Zhao ${ }^{d}$ Zhi Zhang ${ }^{c}$
}

aDepartment of chemotherapy, Nanjing Medical University Affiliated Cancer Hospital, Cancer Institute of Jiangsu Province, Jiangsu Cancer Hospital, Nanjing, 'bepartment of Radiotherapy, Nanjing Medical University Affiliated Cancer Hospital, Cancer Institute of Jiangsu Province, Jiangsu Cancer Hospital, Nanjing, 'Department of Thoracic Surgery, Nanjing Medical University Affiliated Cancer Hospital, Cancer Institute of Jiangsu Province, Jiangsu Cancer Hospital, Nanjing, dDepartment of Respiratory and Critical Care Medicine, The First Affiliated Hospital of Nanjing Medical University, Nanjing, China

\section{Key Words}

Sepia ink oligopeptide $\cdot$ Lung cancer $\cdot$ Apoptosis $•$ Mitochondrial pathway ER stress

\begin{abstract}
Background/Aims: Our previous study suggested the anti-tumor activity of sepia ink oligopeptide (SIO). Here we sought to investigate the underlying molecular mechanism. Methods: Cell proliferation was evaluated by cell counting kit-8 (CCK-8) assay. Cell apoptosis was determined by Annexin V/Propidium Iodide (PI) staining. The mitochondria pathway was characterized by quantification of $\mathrm{BCl}-2$, Bax, Caspase- 9 and Cyto-C. The death receptor pathway was analyzed by determinement of Fas, Caspase- 8 and NIK. The endoplasmic reticulum (ER)-dependent pathway was determined by measurement the expression of CHOP, Caspase-12, GRP78 and Calpain. The associated gene expression was quantified by RT-PCR and protein level was determined by immunoblotting. Results: We demonstrated treatment with structurally modified SIO (CSIO, $5 \mu \mathrm{M})$ significantly inhibited cell proliferation and induced apoptosis in lung cancer cell line A549. The mitochondrial pathway, death receptor pathway and ER stress induced apoptosis were stimulated upon CSIO treatment. The administration with respective inhibitors including midiv-1 (50 $\mu \mathrm{M}$ for $2 \mathrm{~h}$ ), PDTC (20 $\mu \mathrm{M}$ PDTC for $30 \mathrm{~min})$ and ALLN (20 mM ALLN for $5 \mathrm{~h}$ ) readily reversed the apoptosis inducing effect of CSIO. Conclusion: Our data demonstrates that CSIO is capable of induction apoptosis in lung cancer cell line, which is mediated by all three classical apoptotic pathways. Our results warrant further in vivo investigations of the anti-tumor potential of CSIO.
\end{abstract}




\section{Introduction}

Lung cancer is the most common cause of cancer-related death in men and the second most common malignance in women, only after breast cancer [1]. In 2012, 1.8 million new cases of lung cancer were diagnosed and 1.6 million deaths were claimed worldwide. Approximately $4 \sim 17 \%$ of 5-year survival rate was estimated, which heavily dependents on early diagnosis and intervention [2]. Histologically, lung cancer could be divided into two subtypes: non-small cell lung cancer (NSCLC) and small cell lung cancer (SCLC), and NSCLC represented the major proportion of lung cancer cases [3]. The epidemiology investigation has demonstrated that around $85 \%$ new cases of lung cancer are associated with longterm tobacco smoking [4]. Other risk factors include epigenetic and genetic mutations, occupational exposure to radon gas, asbestos and environmental pollutions [5]. Lung cancer may be detected with regular chest radiographs and computed tomography (CT) scans and diagnosed by biopsy with bronchoscopy. The clinical management option with respect to lung cancer greatly depends on the pathological type, stage and overall health condition. Despite that tremendous progression has been archived in understanding the molecular events during tumorigenesis, progression, metastasis and drug resistance of lung cancer, surgery, chemotherapy and radiotherapy are still the mainstay for clinical treatment [6]. Target therapy has been clinically accepted for patients with well-defined genetic mutations, however, the invoked resistance in short period greatly limited its therapeutic values [7]. Most recently, immunotherapy, based on immune checkpoint blockade, has archived enormous success in both hematologic and solid malignancies, but its intrinsically associated auto-immunity disorder imposed therapeutic constraint [8]. Therefore, novel and efficient reagent is still in urgent need for this disease.

Sepia ink is a natural product and has been used in traditional Chinese medicine (TCM), which has been historically used for hemostasis. Accumulating evidences have suggested other therapeutic values of sepia ink in anti-radiation, anti-oxidation, immunomodulation and procoagulation [9]. Most importantly, a previous and elegant study indicated the antitumor activity of sepia ink in BALB/c mice with Meth-A fibrosarcoma, and uncovered the potential of sepia ink as cancer therapeutics [10]. Sepia ink oligopeptide (SIO) is a tripeptide isolated from sepia esculenta by enzymolysis. The peptide in nature displays capacity in improving immune response, inhibiting tumor neo-angiogenesis and metastasis, eradicating tumor cells, inducing apoptosis and arresting cell cycle. Consistent with this notion, our previous data demonstrated that SIO significantly suppressed tumor cell proliferation and induced apoptosis in tumor cell culture. However, the molecular mechanism underlying its anti-tumor effect has not been fully elucidated.

Here we sought to investigate the molecular events in response to SIO treatment. In view of its intrinsic instability as peptide, we synthesized and structurally modified SIO (CSIO) with the basic chemical characteristics preserved. The apoptotic inducing effect of CSIO on lung cancer cells was first consolidated, and then our focus concentrated on the complex and fine-tuned apoptosis regulatory network, which roughly consists of three relative independent while inter-connected pathway: mitochondrial pathway, death receptor pathway and endoplasmic reticulum (ER) stress induced apoptosis [11]. We attempted to determine which pathway is critical for CSIO induced tumor cell apoptosis. The related and key factors in each pathway were carefully examined and specific inhibitors were employed to selectively block respective pathways. This study provided detailed scenario at molecular level during cell apoptosis elicited by SIO derivate treatment. The insightful depiction of the signaling cascade could contritube to strategy leading compound optimization and combination therapeutics.

\section{Materials and Methods}

Synthesis of CSIO peptide

The method to synthesize CSIO was described previously [12]. To improve the stability and bioavailability, here we adopted the peptide cyclization strategy with introduction two homocysteine 


\section{Cellular Physiology Cell Physiol Biochem 2018;45:2095-2106 \begin{tabular}{l|l} 
and Biochemistry POI: 10.1159/000488046 & $\begin{array}{l}\text { C) } 2018 \text { The Author(s). Published by S. Karger AG, Basel } \\
\text { www.karger.com/cpb }\end{array}$
\end{tabular} \\ Published online: March 12, 2018}

flanking the QPK tripeptide. The pentapeptide was synthesized by the solid-phase peptide synthesis (SPPS) method, followed by the cyclization performed via oxidation reaction. The resultant product was characterized by HPLC and LC-MS analysis.

\section{Cell culture}

The human alveolar basal epithelial adenocarcinoma cell A549 was obtained and authenticated by the America Typical Culture Collection (ATCC). Cells were maintained in PRMI-1640 medium supplemented with $10 \%$ fetal bovine serum and $1 \%$ penicillin/streptavidin. Exponentially growing cells were cultured in $37{ }^{\circ} \mathrm{C}$ humidified incubator supplemented with $5 \% \mathrm{CO}_{2}$. Cells were pre-incubated with Mdivi $(50 \mu \mathrm{M}$ for 2 h), Pyrrolidine dithiocarbamate (PDTC, $4 \mu \mathrm{M}$ for $30 \mathrm{~min}$ ) or ALLN (10 $\mathrm{mM}$ for $6 \mathrm{~h}$ ) as indicated respectively. This study was approved by the ethics committee of Nanjing Medical University Affiliated Cancer Hospital.

\section{PCR}

The total RNA was extracted with Trizol reagent (Invitrogen, Carlsbad, CA, USA) in accordance with the manufacturer's instruction. The quality and quantity were determined first before further processing. Each $1 \mu \mathrm{g}$ total RNA was then reverse transcribed into CDNA using the PrimeScript First Strand cDNA Synthesis Kit (Clontech, USA) following the manufacturer's manual. The primers used for RT-PCR were listed as below and relative transcript were quantified by densitometry of agarose gel electrophoresis.

Bcl-2 Forward: 5'-CTGGGAGAACAGGGTACGATAA-3'

Bcl-2 Reverse: 5'-CCCACCGAACTCAAAGAAGG-3'

Bax Forward: 5'-TTTTGCTTCAGGGTTTCATC-3'

Bax Reverse: 5'-GGGACATCAGTCGCTTCAGT-3'

Caspase-9 Forward: 5'-GAACTAACAGGCAAGCAGC-3'

Caspase-9 Reverse: 5'-TTCACCTCCACCATGAAAT-3'

Cyto-C Forward: 5'-ATGGGTGATGTTGAGAAA-3'

Cyto-C Reverse: 5'-TTAAGTCTGCCCTTTCTT-3'

GAPDH Forward: 5'-AATCCCATCACCATCTTCC-3'

GAPDH Reverse: 5'-GAGTCCTTCCACGATACCAA-3'

\section{Cell apoptosis assay}

The exponentially growing cells subjected to indicated treatment were digested with trypsin to prepare single cell suspension in HEPES buffer. Staining with both Annexin V-fluorescein isothiocyanate and Propidium Iodide (PI) (Sigma, St. Louis, MO, USA) were performed in dark at room temperature for 15 min and the cell death was then determined by staining and count the cell number with apoptosis. The results were analyzed by the instrument own software.

\section{Cell Proliferation Assay}

The relative cell proliferation was determined by commercial available CCK-8 Kit (Donjo). Briefly, equal amount of cells was seeded into 96-well plate and subjected to either mock or indicated treatments. For each well, $10 \mu \mathrm{l}$ of CCK-8 solution was added and incubated at $37^{\circ} \mathrm{C}$ for $1 \sim 4 \mathrm{~h}$ dependent on chromogenic reaction. The relative absorbance at 450 was measured and cell viability was calculated.

\section{Immunoblotting}

Cell lysate was prepared form indicated samples in RIPA buffer. The total protein concentration was determined with BCA Protein Assay Kit (Pierce, WI, USA). Equal amount of lysates was loaded and separated by SDS-PAGE electrophoresis. The protein was then transferred to PVDF membrane on ice. After immediate blocking with 5\% milk in TBS buffer supplemented with $0.05 \%$ Tween-20, the membrane was hybridized with specific primary antibody at $4{ }^{\circ} \mathrm{C}$ overnight. The residue antibody dilution was then completely removed by rigorous wash with TBST for $30 \mathrm{~min}$ and subsequently followed by incubation with HRP-labeled secondary antibody at room temperature for $1 \mathrm{~h}$. The second wash was performed and the protein bands were then visualized using enhanced chemiluminiscence reagent (Cwbiotech). The intensity of target bands was quantified by densitometry and normalized to internal reference GAPDH.

Statistical Analysis

All the results in this study were obtained from at least three independent experiments. The variance analysis was performed by one or two-way ANOVA analysis followed by a Tukey's post hoc test with 
SPSS 19.0 software and all the results were expressed as Mean \pm standard deviation (SD). The statistical significance was calculated as $\mathrm{p}$ value, which less than 0.05 was considered as statistically different.

\section{Results}

\section{CSIO significantly induced apoptosis in A549 cell}

Here we first set out to closely inspect the apoptotic pathway in response to SIO treatment, and attempted to uncover the underlying mechanism.We first determined the cell proliferation upon treatment with either mock or CSIO $(5 \mu \mathrm{M})$ for up to $72 \mathrm{~h}$ using the commercial CCK-8 kit. The relative cell viability was remarkably compromised by CSIO co-incubation in a time-dependent manner (decreased up to $21 \pm 1.8 \%$ for $24 \mathrm{~h}, 32 \pm 0.9 \%$ for $48 \mathrm{~h}$ and $34 \pm 1 \%$ for $72 \mathrm{~h}, p<0.01$ ) (Fig. 1A). We next attempted to discriminate whether the effect on cell growth was caused by apoptosis induction. The general cell death was analyzed by Annexin V/PI double-staining immediately after CSIO treatment. The representative stainingpositive cells were shown in upper pane of Fig. 1B. Our results clearly demonstrated that low concentration of CSIO was enough to provoke dramatic apoptosis (increased up to $80 \pm 2.3 \%$ for $24 \mathrm{~h}, 135 \pm 4.3 \%$ for $48 \mathrm{~h}$ and $217 \pm 5.6 \%$ for $72 \mathrm{~h}, p<0.01$ ) (Fig. 1B). It's highly likely that the anti-tumor activity of CSIO could attribute to apoptosis-inducing effect.

\section{CSIO induced mitochondria-mediated} apoptosis in $A 549$

Next, we sought to interrogate the classical apoptotic pathways including mitochondrial pathway, ER stress induced apoptosis and death receptor pathway in lung cancer cells in response to CSIO treatment. In consistent with cytochrome C-mediated apoptotic signaling, our results demonstrated that CSIO treatment induced remarkable elevation of pro-apoptotic BAX, caspase- 9 and cytoplasmic cytochrome $\mathrm{C}$ (Cyto-C) and decreased anti-apoptotic Bcl-2 at both transcript and protein levels $(50 \pm 2 \%$ reduction of Bcl-2 mRNA, $148 \pm 7.6 \%$ increase of BAX, $153 \pm 8.1 \%$ of Caspase- $9,138 \pm 7.6 \%$ of CytoC mRNA, $p<0.01)(53 \pm 3.4 \%$ reduction of $\mathrm{Bcl}-2$ protein, $180 \pm 10.3 \%$ increase of BAX, $36 \pm 4 \%$ of Caspase- $9,47 \pm 4.5 \%$ of cytoplasmic Cyto-C protein, $p<0.01$ ) (Fig. 2A, B). To further validate the crucial role of mitochondrial apoptosis in CSIO-

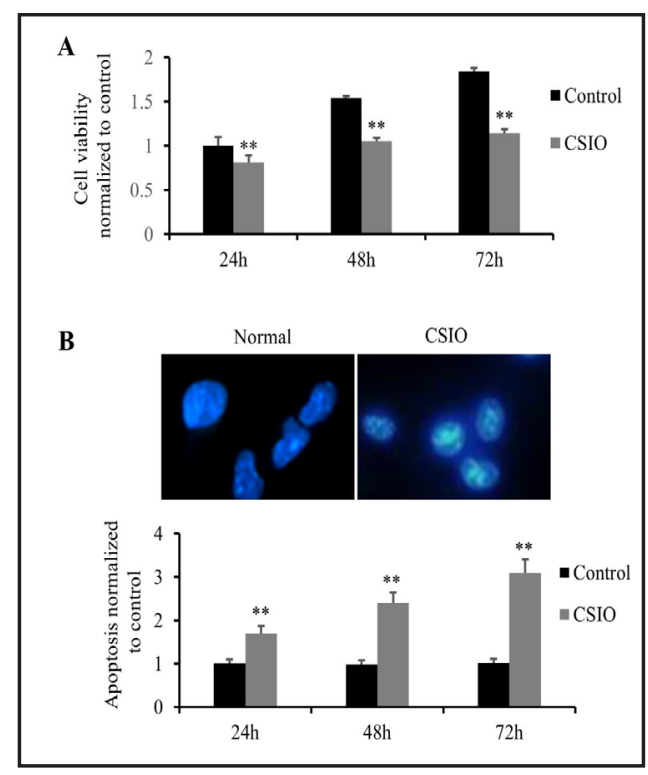

Fig. 1. CSIO inhibits proliferation and induces apoptosis in lung cancer cells. A. The A549 cells were placed on 96 -well plates $\left(1 \times 10^{4}\right.$ cells/ well) and incubated after treatment with $5 \mu \mathrm{M}$ CSIO for up to $72 \mathrm{~h}$. Growth curves of individual CSIO treated and non-treated cells were detected. Points and range lines at different day (24, 48 and $72 \mathrm{~h}$ ) represent mean and SD of three independent experiments in triplicate by CCK-8 kit. OD value was measured at $450 \mathrm{~nm}$ and data demonstrated a significant growth decrease by CSIO ( $\mathrm{p}<0.01)$. B. Annexin-V/propidium iodide double-staining assay was performed to detect the apoptosis levels of A549 cells after treatment with $5 \mu \mathrm{M}$ CSIO for up to $72 \mathrm{~h}$. Relative expression values represent mean and SD from three independent experiments $(\mathrm{p}<0.01)$. The data demonstrated a significant apoptotic increase by CSIO. elicited cell death, here we employed mdivi-1, a selective inhibitor of mitochondrial fission protein, to specifically block mitochondria mediated cell apoptosis [13] without influencing other apoptotic cues. We preliminarily evaluated the potential impact on mitochondrial dynamics via interrogation of relevant gene expressions. As shown in Fig. 3A, midiv-1 specifically inhibited Drp-1 expression whereas barely 
Fig. 2. CSIO induces apoptosis via mitochondriadependent pathway in lung cancer cells. A. The A549 cells were incubated after treatment with $5 \mu \mathrm{M}$ CSIO for $72 \mathrm{~h}$. The associated genes of mitochondria-dependent pathway (Bcl-2, Bax, Caspase- 9 and CytoC) were detected by PCR. Relative expression values represent mean and SD from three independent experiments $(p<0.01)$. The data demonstrated a significant activation of mitochondria-dependent pathway by CSIO. B. Proteins of Bcl-2, Bax, Caspase-9 and Cyto-C expression were analyzed by Western Blot. The data also demonstrated a significant activation of mitochondria-dependent pathway by CSIO.

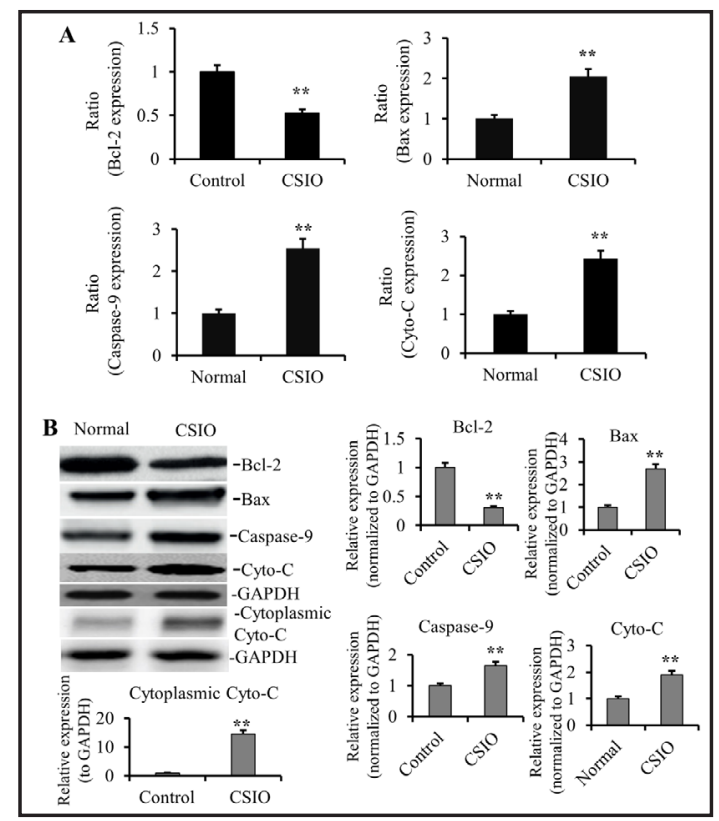

Fig. 3. Apoptosis is suppressed via inhibition of mitochondria-dependent pathway in lung cancer cells. A. The changes of mitochondrial dynamics in lung cancer cells after treatment of Mdivi-1. The A549 cells were treated with mitochondria inhibitor-50 $\mu \mathrm{M}$ Mdivi-1 for $2 \mathrm{~h}$. The associated genes of mitochondrial dynamics relative proteins (Drp1, Fis1, Mfn1 and OPA1) were detected by PCR. B. The A549 cells were treated with mitochondria inhib-

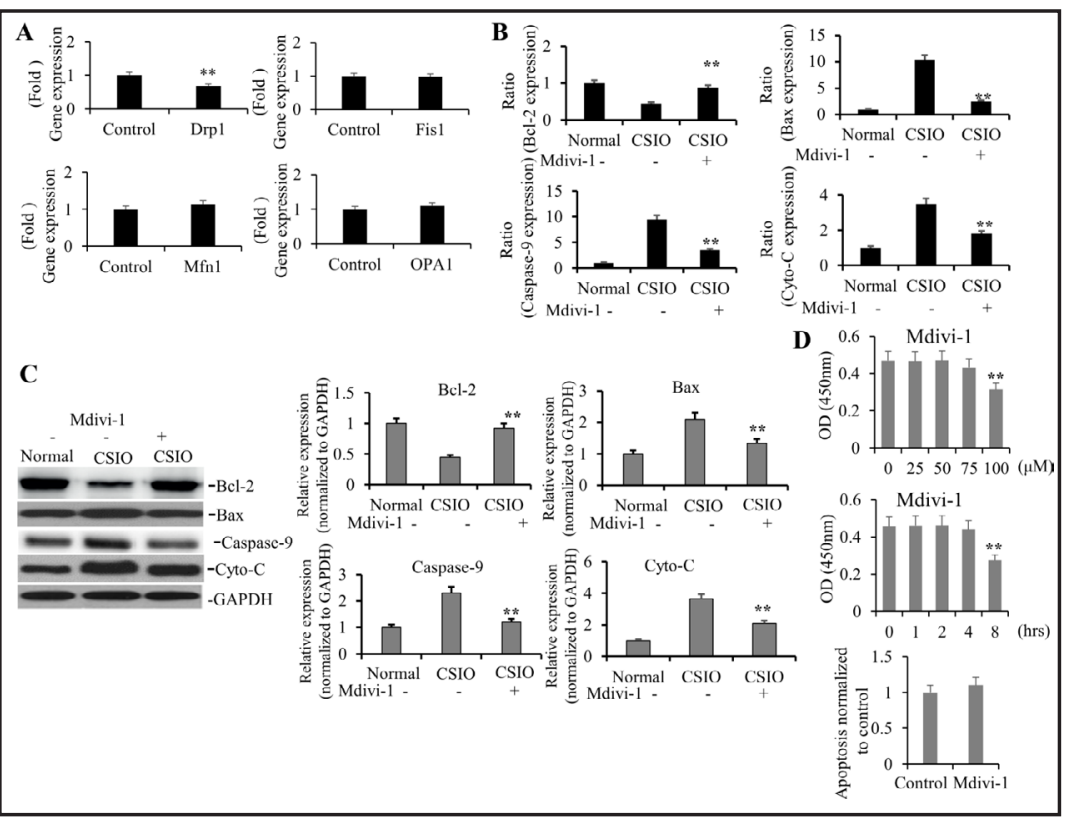
itor- $50 \mu \mathrm{M}$ Mdivi- 1 for 2

$\mathrm{h}$, then incubated after treatment with $5 \mu \mathrm{M}$ CSIO for $72 \mathrm{~h}$. The associated genes of mitochondria-dependent pathway (Bcl-2, Bax, Caspase-9 and Cyto-C) were detected by PCR. The data demonstrated a significant decrease of activation apoptosis of CSIO by inhibiting mitochondria. C. Meanwhile the proteins of Bcl-2, Bax, Caspase- 9 and Cyto-C expression by treatment of $50 \mu \mathrm{M}$ for $2 \mathrm{~h}$ Mdivi- 1 were analyzed by Western Blot. The data also demonstrated a significant decrease of activation apoptosis of CSIO by inhibiting mitochondria. D. Midivi-1 has no influence on the apoptosis of lung cancer cells. On the top: the A549 cells were placed on 96-well plates $\left(1 \times 10^{4}\right.$ cells/well) and incubated after treatment with Midivi-1 $0,25,50,75,100 \mu \mathrm{M}$ for 2 h). Growth curves of individual cells were detected by CCK- 8 kit. In the middle: the A549 cells were placed on 96-well plates $\left(1 \times 10^{4}\right.$ cells/well) and incubated after treatment with Midivi-1 (50 $\mu \mathrm{M}$ for $0,1,2,4$ and $8 \mathrm{~h})$. Growth curves of individual cells were detected by CCK-8 kit. On the below: Annexin V/propidium iodide double-staining assay was performed to detect the apoptosis levels of A549 cells after treatment with Midivi-1 (50 $\mu \mathrm{M}$ for $2 \mathrm{~h}$ ). Relative expression values represent mean and SD from three independent experiments.

\section{KARGER}


Fig. 4. CSIO induces apoptosis via death pathway in lung cancer cells. A. The A549 cells were incubated after treatment with $5 \mu \mathrm{M}$ CSIO for $72 \mathrm{~h}$. The associated genes of mitochondria-dependent pathway (Fas, Caspase- 8 and NIK) were detected by PCR. Relative expression values represent mean and SD from three independent experiments $(\mathrm{p}<0.01)$. The data demonstrated a significant activation of death pathway by CSIO. B. Proteins of Fas, Caspase-8 and NIK expression were analyzed by Western Blot. The data also demonstrated a significant activation of death pathway by CSIO.

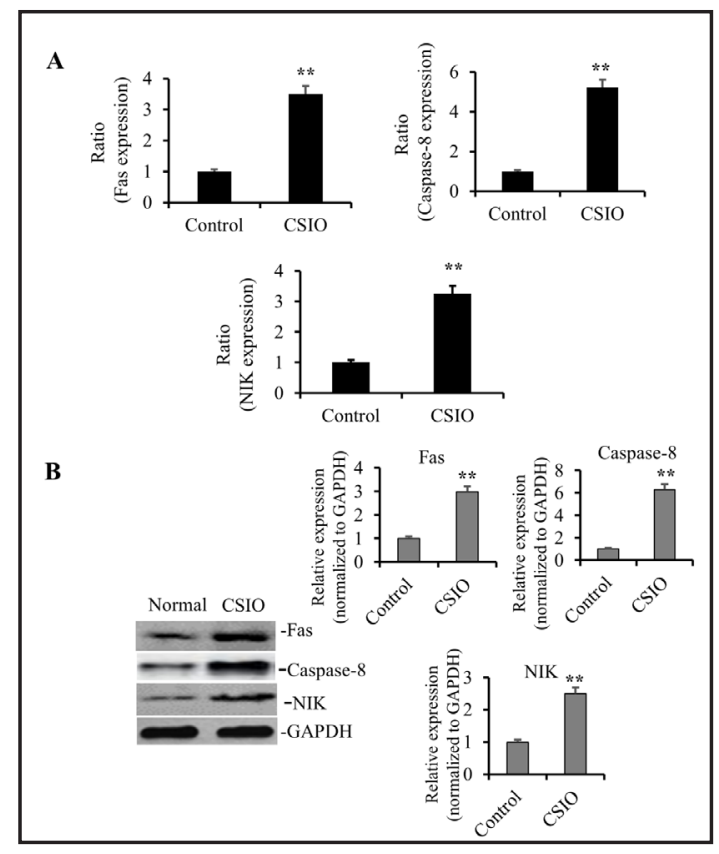

Fig. 5. Apoptosis is suppressed via inhibition of death pathway in lung cancer cells. A. The A549 cells were treated with $\mathrm{NF}-\kappa \mathrm{B}$ inhibitor- 20 $\mu \mathrm{M}$ PDTC for $30 \mathrm{~min}$, then incubated after treatment with $5 \mu \mathrm{M}$ CSIO for $72 \mathrm{~h}$. The associated genes of death pathway (Fas, Caspase-8 and NIK) were detected by PCR. Relative expression values represent mean and SD from

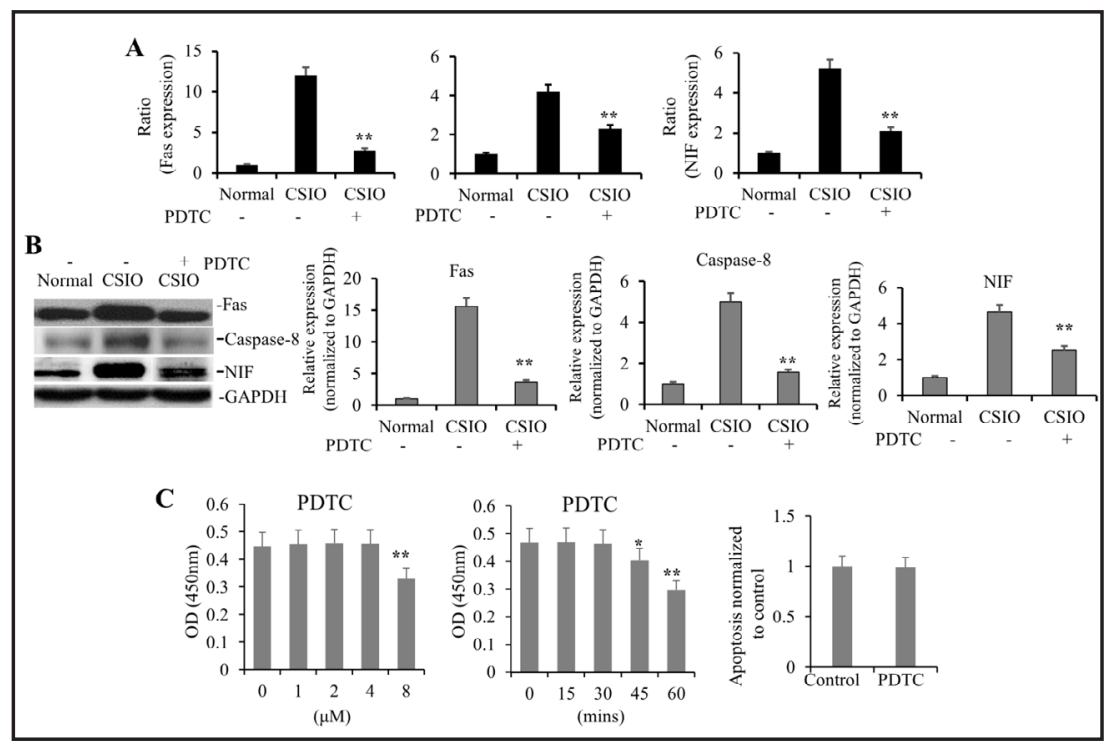
three independent experiments $(\mathrm{p}<0.01)$. The data demonstrated a significant decrease of activation apoptosis of CSIO by inhibiting NF-кB. B. Meanwhile the proteins of Fas, Caspase- 8 and NIK expression by treatment of $4 \mu$ M PDTC for $30 \mathrm{~min}$ were analyzed by Western Blot. The data also demonstrated a significant decrease of activation apoptosis of CSIO by inhibiting NF-кB. C. PDTC has no influence on the apoptosis of lung cancer cells. On the left: the A549 cells were placed on 96 -well plates $\left(1 \times 10^{4}\right.$ cells/well $)$ and incubated after treatment with PDTC $(0,1,2,4,8 \mu \mathrm{M}$ for 30 mins). Growth curves of individual cells were detected by CCK-8 kit. In the middle: the A549 cells were placed on 96-well plates $(1 \times 104$ cells/well $)$ and incubated after treatment with PDTC ( $4 \mu \mathrm{M}$ for $0,15,30,45$ and 60 mins). Growth curves of individual cells were detected by CCK-8 kit. On the right: Annexin V/propidium iodide double-staining assay was performed to detect the apoptosis levels of A549 cells after treatment with PDTC ( $4 \mu \mathrm{M}$ for $30 \mathrm{mins}$ ). Relative expression values represent mean and SD from three independent experiments.

affected Fis1, Mfn and OPA1. In this setting, all molecular events including alterations in Bcl-2, Bax, caspase- 9 and cyto-C expressions were reversed upon co-treatment with mdivi-1 
Fig. 6. CSIO induces apoptosis via ER-dependent pathway in lung cancer cells. A. The A549 cells were incubated after treatment with $5 \mu \mathrm{M}$ CSIO for $72 \mathrm{~h}$. The associated genes of mitochondria-dependent pathway (CHOP, Caspase-12, GRP78 and Calpain) were detected by PCR. Relative expression values represent mean and SD from three independent experiments $(\mathrm{p}<0.01)$. The data demonstrated not a significant activation of ER-dependent pathway by CSIO. B. Proteins of CHOP, Caspase-12, GRP78 and Calpain expression were analyzed by Western Blot. The data also demonstrated not a significant activation of ER-dependent pathway by CSIO.

(37 $\pm 1.8 \%$ increase of Bcl-2 mRNA, $76 \pm 6.4 \%$ reduction of $\mathrm{BAX}, 72 \pm 7 \%$ of Caspase-9, $87 \pm 5.1 \%$ of Cyto-C mRNA in comparison to mock treatment, $p<0.01)(47 \pm 3.2 \%$ increase of Bcl-2 protein, $91 \pm 8.3 \%$ reduction of BAX, 79 $\pm 8 \%$ of Caspase- $9,43 \pm 3.4 \%$

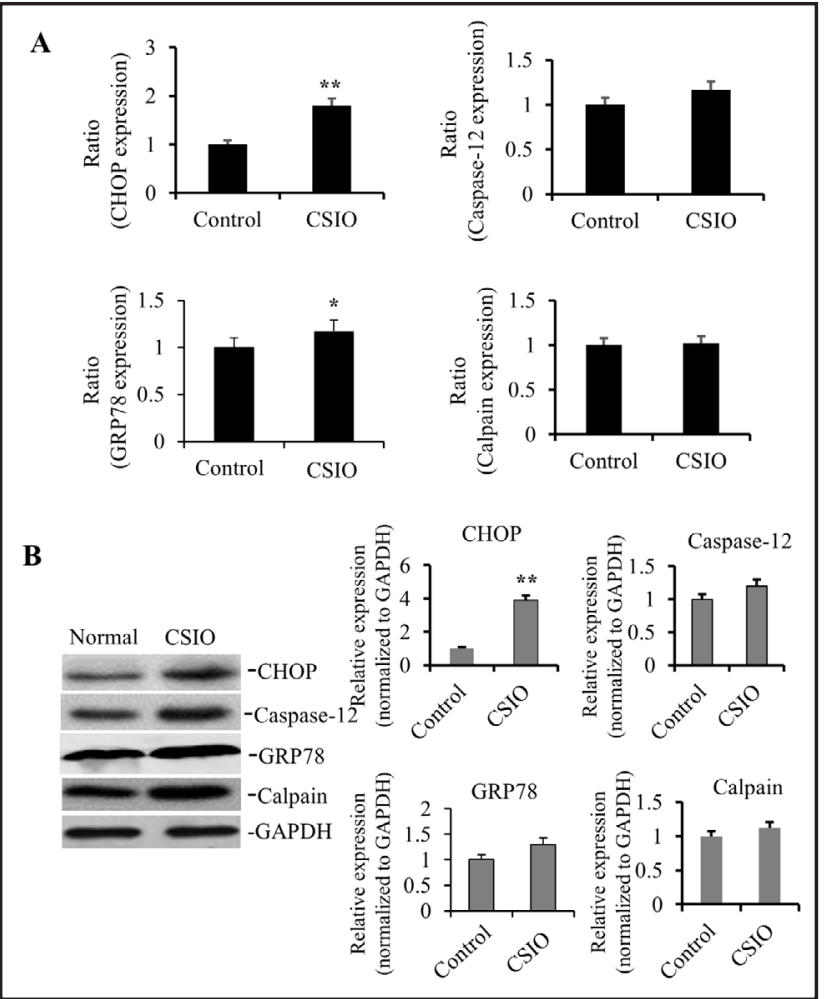
of Cyto-C protein in comparison to mock treatment, $p<0.01$ ) (Fig. 3B, C). We have further ruled out the potential cytotoxicity of mdivi-1 (50 $\mu \mathrm{M})$ in our system. Although slight inhibitory effect on cell proliferation was observed with high concentration of midiv-1 ( $\sim 30 \%$ reduction in cell viability with $100 \mu \mathrm{M}$ midiv-1), the dosage we adopted in this study showed none effects on both cell growth and apoptosis (Fig. 3D). Therefore, our data indicated an important role of cyto-C mediated cell apoptosis in CSIO cytotoxicity against lung cancer cells.

\section{CSIO induced death receptor pathway-mediated apoptosis in A549}

Despite the above mentioned critical role of mitochondria pathway in CSIO induced apoptosis, we could not simply exclude the potential contribution of other cellular apoptotic signaling to CSIO-induced cell death. Next, we focused on the death receptor pathway and interrogated the key signaling nodes including Fas, Caspase-8 and NIK upon CSIO treatment. As shown in Fig. 4A and B, CSIO challenge markedly increased expressions of Fas, caspase-8 and NIK along the death receptor pathway (234 $\pm 18.4 \%$ increase of Ras mRNA, 402 $\pm 26.3 \%$ of Caspase-8, 205 $\pm 18.6 \%$ of NIK respectively, $p<0.01)$; (197 $\pm 19.2 \%$ increase of Fas protein, $396 \pm 40.1 \%$ of Caspase-8, $162 \pm 13.4 \%$ of NIK respectively, $p<0.01)$. The involvement of death receptor mediated apoptosis in response to CSIO treatment was further consolidated with unique inhibitor PDTC [14]. Administration with PDTC significantly reversed the expression alterations in Fas, caspase- 8 and NIK ( $87 \pm 5 \%$ reduction of Fas mRNA, $54 \pm 2.1 \%$ of Caspase-8, $68 \pm 4.3 \%$ of NIK in comparison with mock treatment, $p<0.01$ ) (81 $\pm 4.6 \%$ reduction of Fas protein, $73 \pm 6.2 \%$ of Caspase- $8,48 \pm 5 \%$ of NIK in comparison with mock treatment, $p<0.01$ ) (Fig. 5A and B). Only slight inhibitory effect was observed with extremely high concentration of PDTC (Fig. 5C). Likewise, our data supported an indispensable role of death receptor pathway in mediating CSIO-induced cell apoptosis in addition to mitochondrial signaling.

\section{CSIO also stimulated ER pathway-mediated apoptosis in A549}

In addition to mitochondrial pathway and death receptor pathway, we further characterized the ER stress pathway which was increasingly recognized to play critical role 
Fig. 7. Apoptosis is suppressed via inhibition of ER-dependent pathway in lung cancer cells. A. The A549 cells were treated with calpain inhibitor- $20 \mathrm{mM}$ ALLN for $5 \mathrm{~h}$, then incubated after treatment with $5 \mu \mathrm{M}$ CSIO for $72 \mathrm{~h}$. The associated genes of mitochondria-dependent pathway (CHOP, Caspase-12, GRP78 and Calpain) were detected by PCR. Relative expression values represent mean and SD from three independent experiments $(\mathrm{p}<0.01)$. The data demonstrated not a significant decrease of activation apoptosis of CSIO by inhibiting ER pathway. B. Mean-

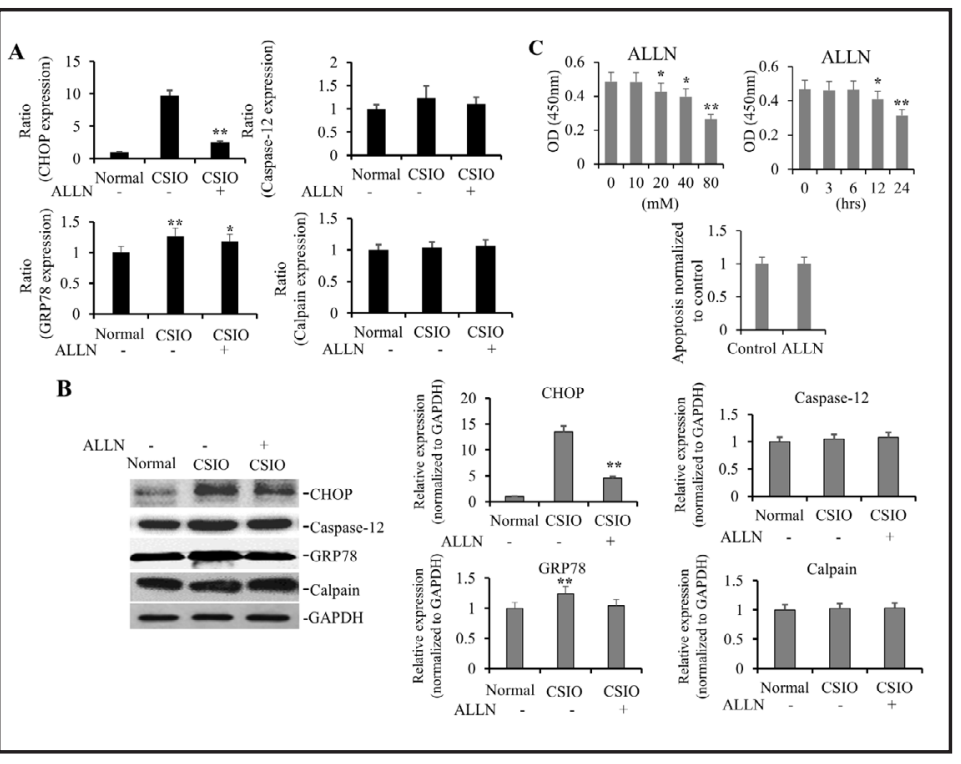
while the proteins of CHOP, Caspase-12, GRP78 and Calpain expression by treatment of $10 \mathrm{mM}$ ALLN for $6 \mathrm{~h}$ were analyzed by Western Blot. The data also demonstrated a significant decrease of activation apoptosis of CSIO by inhibiting ER pathway. C. ALLN has no influence on the apoptosis of lung cancer cells. On the top left: the A549 cells were placed on 96-well plates $\left(1 \times 10^{4}\right.$ cells/well) and incubated after treatment with ALLN $(0,10,20,40,80 \mathrm{mM}$ for $6 \mathrm{~h})$. Growth curves of individual cells were detected by CCK-8 kit. On the top right: the A549 cells were placed on 96-well plates $\left(1 \times 10^{4}\right.$ cells/well) and incubated after treatment with ALLN (10 mM for 0, 3, 6, 12 and 24 h). Growth curves of individual cells were detected by CCK-8 kit. On the below: Annexin-V/propidium iodide double-staining assay was performed to detect the apoptosis levels of A549 cells after treatment with ALLN (10 mM for $6 \mathrm{~h}$ ). Relative expression values represent mean and SD from three independent experiments.

in stimulation of cell apoptosis [15] and might be involved in the CSIO-induced cell death in lung cancer cell lines. To this purpose, the critical effectors in this direction, including CHOP, Calpain and Caspase-12, were determined at both transcriptional and translational levels. The provoked ER stress was unambiguously demonstrated by the significant increase in CHOP mRNA and protein in response to CSIO treatment as shown in Fig. $6 \mathrm{~A}$ and B $(76 \pm 4.5 \%$ increase of CHOP mRNA, $\mathrm{p}<0.01)(278 \pm 18.4 \%$ increase of CHOP protein, $\mathrm{p}<0.01)$. However, no obvious inductions in Calpain and Caspase- 12 were observed in CSIO-treated A549, which indicated an independence of CSIO-stimulated cell death on this sub-pathway. Similarly, the Calpain-specific inhibitor, ALLN [16], significantly abrogated the CHOP induction imposed by CSIO-treatment $(78.4 \pm 6.4 \%$ increase of CHOP mRNA, $\mathrm{p}<0.01 ; 71.3 \pm 2.4 \%$ increase of CHOP protein, $\mathrm{p}<0.01$; Fig. 7A and B). Similarly, only slight inhibitory effect was observed with extremely high concentration of ALLN (Fig. 7C). Our results indicated CSIO-induced cell apoptosis partially mediated by ER stress pathway, which predominantly attributed to CHOP activation.

\section{Discussion}

Lung cancer is the most common malignance in human with high mortality and morbidity [17]. The etiology of this disease has been well characterized in comparison with other tumors, which predominately attribute to tobacco smoking, occupational exposure, environmental pollution and genetic or epigenetic mutations [18]. The overall survival heavily depends on early screening, diagnosis and interventions. A pilot study suggested that low-dose CT scan accounted for approximate $20 \%$ reduction in mortality [19]. Surgical 
resection is the most efficient option for early diagnosed patients and associated with relatively optimistic prognosis. Chemotherapy and radiotherapy are the first-line treatments for patients who are not amenable to surgery with local advance malignance [2]. Target drugs are applicable for patients with well-defined genetic mutations such as EGFR, KRAS and ALK [7]. However, most patients develop resistance and rapid relapse, which largely compromises its therapeutic effect. Immunotherapy is the emerging regime for clinical management of both hematologic and solid tumors, which harnesses patient's own immune system to eradicate tumor cells. The preliminary clinical trial with immune checkpoint inhibitors against PD-1/PD-L1 axis showed great benefit in increasing the overall survival, in comparison with docetaxel in non-small cell lung cancer patients, which led to immediate approval of nivolumab and pembrolizumab by FDA [20]. The randomized trial also suggested that only a small portion of lung cancer patients could benefit from this therapeutics, which necessitates intense search for sensitive and reliable biomarkers. Despite of a variety of clinical options available, the novel therapeutics are still under intensive exploitation.

Sepia ink is a natural product and historically used for hemostasis in TCM [21]. Its medicinal value has been increasingly exploited in a variety of human diseases. For instance, therapeutic effect of low molecular weight chitosan containing sepia ink has been demonstrated in ethanol-induced gastric ulcer in rats [22]. Zhang et al. showed the beneficial effect of chitin and sepia ink hybrid sponge on the healing of burning wound in rat model via promoting the phagocytosis ability of macrophages [23]. Moreover, sepia ink extract provided a curative effect and anti-oxidative capacity on bile duct ligation, and could ameliorate the complications of live cholestasis [24]. Intriguingly, in combination with anti-fungal agent, sepia ink extract displayed therapeutic effect against invasive pulmonary aspergillosis [25]. The anti-tumor activity of sepia ink has been demonstrated in vitro by several investigations as well [26-28]. However, the most therapeutic potentials of sepia ink have been interrogated with crude extract, since the precise composition of sepia ink had not been fully characterized until now. Some effective compositions identified in sepia ink extract include polysaccharide, peptide and small molecule chemicals. Our previous study has demonstrated a tripeptide isolated from sepia ink induced apoptosis in prostate cancer cells in vitro for the first time [10]. However, the detailed molecular mechanism underlying the apoptosis elicited by SIO treatment has not been fully elucidated. Here we employed CSIO with cyclization chemical modification instead of SIO in consideration of improved stability and enhanced cell permeability, as measured with fluorescent probe-labelling technology [12]. Our results evaluated the anti-tumor property of this derived oligopeptide in vitro and demonstrated significant apoptosis induced by CSIO in lung cancer cell A549, which suggested a potential therapeutic effect of CSIO in this disease.

In this study, we concentrated on understanding the molecular mechanism underlying CSIO-induced cell apoptosis in lung cancer. We systematically investigated an array of molecular events during the apoptotic process, which is well-coordinated and mediated mainly by three well-recognized pathways [29]. In addition to its cellular energy factory role, mitochondria also served as central hub in regulating cell apoptosis [30]. The release of cyto- $\mathrm{C}$ from mitochondria into the cytosol leads to irreversible apoptotic signaling cascade [31]. The mitochondrial membrane permeability is under strict control of Bcl-2 family and counter-acted by Bax [32]. Our previous study preliminarily demonstrated that the strong cell penetration of stable CSIO in A549 and H1299 inhibited cell proliferation and induced cell apoptosis via down-regulating anti-apoptotic Bcl-2 and up-regulating pro-apoptotic P53 and caspase-3 [12]. In line with this observation, here we consolidated the suppression of Bcl-2 in response to CSIO in A549. Furthermore, we have characterized increased Bax, Caspase-12 and cytoplasmic cyto-C upon CSIO treatment. Our results unambiguously demonstrated that CSIO stimulated apoptosis via the mitochondria pathway. Simultaneously, we employed mdivi-1, a cell-permeable selective inhibitor of mitochondrial division DRP (dynamin-related GTPase) and inhibitor of the mitochondrial division dynamin (Dnm1), to specifically block the mitochondrial pathway [33]. In this setting, mitochondrial pathway activation has been completely abolished. 
Next, we sought to clarify whether other pathways were involved in CSIO-stimulated cell death in A549 as well. In addition to mitochondria pathway, death receptor pathway also played a critical role in apoptotic signaling [34]. We have examined an array of key factors along this cascade in response to CSIO challenge. Our data clearly demonstrated that CSIO treatment significantly up-regulated Fas, caspase- 8 and NIK at both transcript and protein levels, which indicated an indispensable role of death receptor pathway in mediating CSIO induced apoptosis in A549. Caspase cascade eventually activates NIK and leads to NF- $\kappa B$ dissociation and release [35]. The nucleus translocated NF- $\kappa B$ subsequently stimulates expression of downstream genes in promotion apoptotic process. Likewise, we employed the NF- $\kappa B$ specific inhibitor PDTC, which readily abrogated death receptor pathway activation by CSIO treatment [14]. Therefore, our results added another dimension to the apoptotic effect of CSIO in lung cancer. Noteworthily, the detailed mechanism underlying CSIO-activated death receptor pathway is still elusive at present and requires further elucidations. In view of the critical role of Smac in relieving the inhibitory effect of the inhibitor of apoptosis protein (IAP) and eliciting death receptor pathway-mediated cell death [36], we hypothesized here that CSIO might function in a similar way to directly interact with IAP, which required experimental validation in future studies.

At last, we evaluated the role of ER stress in CSIO-induced cell apoptosis [15, 37]. Overloaded or malfunctioned ER stimulates release of $\mathrm{Ca}^{2+}$ into the cytosol, which in turn activates Calpain. The active Calpain translocates to ER membrane and promotes cleavage of caspase-12. Simultaneously, CHOP expression is up-regulated in response to ER stress. CHOP stimulates Bax transportation to the mitochondria and suppresses Bcl-2 expression, which contributes to mitochondrial pathway mediated apoptosis [38]. In addition, CHOP activation decreases intracellular glutathione content, disturbs redox homeostasis and induces apoptosis [39]. We have observed dramatic increase of CHOP upon CSIO treatment and slight changes in both caspase-12 and Calpain. Application of Calpain inhibitor ALLN [16] significantly suppressed CHOP up-regulation and related cell apoptosis. Our data also supported an important role of ER stress in mediating CSIO-elicited apoptosis. Although our observations indicated that activation of all three pathways converging on cell death in response to CSIO, more firm conclusion remains to be reached via either systematic interrogation by microarray or thorough experimental validations.

\section{Conclusion}

In summary, we have extensively characterized cell apoptotic events in response to CSIO treatment. Our results demonstrate all the three classical pathways potentially contribute to CSIO elicited apoptotic effect. Our in vitro study also warrants anti-tumor investigation in tumor animal model in vivo.

\section{Acknowledgements}

This study was supported by the Young Talent Medical Funding of Jiangsu Province (\#QNRC2016655).

\section{Disclosure Statement}

The authors declare that there is no conflict of interests. 


\section{Cellular Physiology Cell Physiol Biochem 2018;45:2095-2106 \begin{tabular}{l|l|l} 
and Biochemistry & $\begin{array}{l}\text { DOI: 10.1159/000488046 } \\
\text { Published online: March 12, } 2018\end{array}$ & $\begin{array}{l}\text { C) } 2018 \text { The Author(s). Published by S. Karger AG, Basel } \\
\text { www.karger.com/cpb }\end{array}$ \\
\hline
\end{tabular}}

Wang et al.: CSIO Induces Apoptosis in Lung Cancer Cells

\section{References}

1 Siegel RL, Miller KD, Jemal A: Cancer statistics, 2016 CA Cancer J Clin 2016;66:7-30.

-2 Hirsch FR, Scagliotti GV, Mulshine JL, Kwon R, Curran WJ, Jr., Wu YL, Paz-Ares L: Lung cancer: current therapies and new targeted treatments. Lancet 2016;10.1016/S0140-6736(16)30958-8

3 Rabe KF: Lung cancer staging: a true story. Lancet Respir Med 2015;3:258-259.

-4 Jung KJ, Jeon C, Jee SH: The effect of smoking on lung cancer: ethnic differences and the smoking paradox. Epidemiol Health 2016;38:e2016060.

5 Baranov VS, Glotov OS, Baranova EV: [Genetic and epigenetic news in gerontology]. Adv Gerontol 2014;27:247-256.

-6 Tsao AS, Scagliotti GV, Bunn PA, Jr., Carbone DP, Warren GW, Bai C, de Koning HJ, Yousaf-Khan AU, McWilliams A, Tsao MS, Adusumilli PS, Rami-Porta R, Asamura H, Van Schil PE, Darling GE, Ramalingam SS, Gomez DR, Rosenzweig KE, Zimmermann S, Peters S, Ignatius Ou SH, Reungwetwattana T, Janne PA, Mok TS, Wakelee HA, Pirker R, Mazieres J, Brahmer JR, Zhou Y, Herbst RS, Papadimitrakopoulou VA, Redman MW, Wynes MW, Gandara DR, Kelly RJ, Hirsch FR, Pass HI: Scientific Advances in Lung Cancer 2015. J Thorac Oncol 2016;11:613-638.

7 Cafarotti S, Lococo F, Froesh P, Zappa F, Andre D: Target Therapy in Lung Cancer. Adv Exp Med Biol 2016;893:127-136.

8 Tartour E, Zitvogel L: Lung cancer: potential targets for immunotherapy. Lancet Respir Med 2013;1:551563.

-9 Ruiz-Ruiz F, Mancera-Andrade EI, Iqbal HM: Marine-Derived Bioactive Peptides for Biomedical Sectors: A Review. Protein Pept Lett 2017;24:109-117.

10 Huang F, Yang Z, Yu D, Wang J, Li R, Ding G: Sepia ink oligopeptide induces apoptosis in prostate cancer cell lines via caspase-3 activation and elevation of Bax/Bcl-2 ratio. Mar Drugs 2012;10:2153-2165.

11 Larsen BD, Sorensen CS: The caspase-activated DNase: apoptosis and beyond. FEBS J 2016;10.1111/ febs. 13970

12 Zhang Z, Sun L, Zhou G, Xie P, Ye J: Sepia ink oligopeptide induces apoptosis and growth inhibition in human lung cancer cells. Oncotarget 2017;8:23202-23212.

-13 Bordt EA, Clerc P, Roelofs BA, Saladino AJ, Tretter L, Adam-Vizi V, Cherok E, Khalil A, Yadava N, Ge SX, Francis TC, Kennedy NW, Picton LK, Kumar T, Uppuluri S, Miller AM, Itoh K, Karbowski M, Sesaki H, Hill RB, Polster BM: The Putative Drp1 Inhibitor mdivi-1 Is a Reversible Mitochondrial Complex I Inhibitor that Modulates Reactive Oxygen Species. Dev Cell 2017;40:583-594 e586.

14 Kan S, Zhou H, Jin C, Yang H: Effects of PDTC on NF-kappaB expression and apoptosis in rats with severe acute pancreatitis-associated lung injury. Int J Clin Exp Med 2015;8:3258-3270.

15 Song S, Tan J, Miao Y, Li M, Zhang Q: Crosstalk of Autophagy and Apoptosis: Involvement of the Dual Role of Autophagy Under ER Stress. J Cell Physiol 2017;10.1002/jcp.25785

16 Honma Y, Harada M: Sorafenib enhances proteasome inhibitor-mediated cytotoxicity via inhibition of unfolded protein response and keratin phosphorylation. Exp Cell Res 2013;319:2166-2178.

17 Goldstraw P, Ball D, Jett JR, Le Chevalier T, Lim E, Nicholson AG, Shepherd FA: Non-small-cell lung cancer. Lancet 2011;378:1727-1740.

18 Dela Cruz CS, Tanoue LT, Matthay RA: Lung cancer: epidemiology, etiology, and prevention. Clin Chest Med 2011;32:605-644.

19 Goldstraw P, Chansky K, Crowley J, Rami-Porta R, Asamura H, Eberhardt WE, Nicholson AG, Groome P, Mitchell A, Bolejack V, International Association for the Study of Lung Cancer S, Prognostic Factors Committee AB, Participating I, International Association for the Study of Lung Cancer S, Prognostic Factors Committee Advisory B, Participating I: The IASLC Lung Cancer Staging Project: Proposals for Revision of the TNM Stage Groupings in the Forthcoming (Eighth) Edition of the TNM Classification for Lung Cancer. J Thorac Oncol 2016;11:39-51.

20 Kumar R, Collins D, Dolly S, McDonald F, O’Brien ME, Yap TA: Targeting the PD-1/PD-L1 axis in non-small cell lung cancer. Curr Probl Cancer 2016;10.1016/j.currproblcancer.2016.12.002.

21 Zhong JP, Wang G, Shang JH, Pan JQ, Li K, Huang Y, Liu HZ: Protective effects of squid ink extract towards hemopoietic injuries induced by cyclophosphamine. Mar Drugs 2009;7:9-18.

-22 Zhang W, Liu K, Li L, Li Y, Sui X, Rao Y, Wu J, Wu Q: Therapeutic effect of low molecular weight chitosan containing sepia ink on ethanol-induced gastric ulcer in rats. Acta Cir Bras 2016;31:813-820. 


\section{Cellular Physiology Cell Physiol Biochem 2018;45:2095-2106

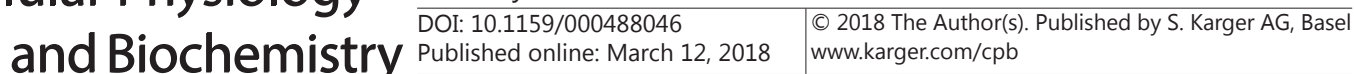

Wang et al.: CSIO Induces Apoptosis in Lung Cancer Cells

23 Zhang W, Wang Y, Sui X, Sun Y, Chen D: Effects of chitin and sepia ink hybrid sponge on the healing of burning wound rats and its impact on macrophages in vitro. Acta Cir Bras 2016;31:119-125.

-24 Saleh H, Soliman AM, Mohamed AS, Marie MA: Antioxidant Effect of Sepia Ink Extract on Extrahepatic Cholestasis Induced by Bile Duct Ligation in Rats. Biomed Environ Sci 2015;28:582-594.

-25 Fahmy SR, Soliman AM, Ali EM: Antifungal and antihepatotoxic effects of sepia ink extract against oxidative stress as a risk factor of invasive pulmonary aspergillosis in neutropenic mice. Afr J Tradit Complement Altern Med 2014;11:148-159.

-26 Soliman AM, Fahmy SR, El-Abied SA: Anti-neoplastic activities of Sepia officinalis ink and Coelatura aegyptiaca extracts against Ehrlich ascites carcinoma in Swiss albino mice. Int J Clin Exp Pathol 2015;8:3543-3555.

-27 Liu HZ, Xiao W, Gu YP, Tao YX, Zhang DY, Du H, Shang JH: Polysaccharide from Sepia esculenta ink and cisplatin inhibit synergistically proliferation and metastasis of triple-negative breast cancer MDA-MB-231 cells. Iran J Basic Med Sci 2016;19:1292-1298.

28 El Arbi M, Ketata E, Neifar A, Mihoubi W, Gupta GK, Pigeon P, Top S, Gargouri A, Jaouen G: Aryl butenes active against K562 cells and lacking tyrosinase inhibitory activity as new leads in the treatment of leukemia. Mini Rev Med Chem 2017;10.2174/1389557517666170208142254

29 Evan GI, Vousden KH: Proliferation, cell cycle and apoptosis in cancer. Nature 2001;411:342-348.

30 Li MX, Dewson G: Mitochondria and apoptosis: emerging concepts. F1000Prime Rep 2015;7:42.

31 Zhang HY, Liang F, Wang F, Zhang JW, Wang L, Kang XG, Wang J, Duan QL: In vitro Effects of HAS-2 Gene Silencing on the Proliferation and Apoptosis of the MCF-7 Human Breast Cancer Cell Line. Cell Physiol Biochem 2016;40:807-817.

32 Kang XH, Zhang JH, Zhang QQ Cui YH, Wang Y, Kou WZ, Miao ZH, Lu P, Wang LF, Xu ZY, Cao F: Degradation of Mcl-1 through GSK-3beta Activation Regulates Apoptosis Induced by Bufalin in Non-Small Cell Lung Cancer H1975 Cells. Cell Physiol Biochem 2017;41:2067-2076.

-33 Gao D, Yang J, Wu Y, Wang Q Wang Q Lai EY, Zhu J: Targeting Dynamin 2 as a Novel Pathway to Inhibit Cardiomyocyte Apoptosis Following Oxidative Stress. Cell Physiol Biochem 2016;39:2121-2134.

-34 Sartorius U, Schmitz I, Krammer PH: Molecular mechanisms of death-receptor-mediated apoptosis. Chembiochem 2001;2:20-29.

-35 Boutaffala L, Bertrand MJ, Remouchamps C, Seleznik G, Reisinger F, Janas M, Benezech C, Fernandes MT, Marchetti S, Mair F, Ganeff C, Hupalowska A, Ricci JE, Becher B, Piette J, Knolle P, Caamano J, Vandenabeele P, Heikenwalder M, Dejardin E: NIK promotes tissue destruction independently of the alternative NFkappaB pathway through TNFR1/RIP1-induced apoptosis. Cell Death Differ 2015;22:2020-2033.

-36 Li L, Thomas RM, Suzuki H, De Brabander JK, Wang X, Harran PG: A small molecule Smac mimic potentiates TRAIL- and TNFalpha-mediated cell death. Science 2004;305:1471-1474.

-37 Gan PP, Zhou YY, Zhong MZ, Peng Y, Li L, Li JH: Endoplasmic Reticulum Stress Promotes Autophagy and Apoptosis and Reduces Chemotherapy Resistance in Mutant p53 Lung Cancer Cells. Cell Physiol Biochem 2017;44:133-151.

-38 Carpio MA, Michaud M, Zhou W, Fisher JK, Walensky LD, Katz SG: BCL-2 family member BOK promotes apoptosis in response to endoplasmic reticulum stress. Proc Natl Acad Sci U S A 2015;112:7201-7206.

-39 Xu X, Liu T, Zhang A, Huo X, Luo Q Chen Z, Yu L, Li Q, Liu L, Lun ZR, Shen J: Reactive oxygen speciestriggered trophoblast apoptosis is initiated by endoplasmic reticulum stress via activation of caspase-12, CHOP, and the JNK pathway in Toxoplasma gondii infection in mice. Infect Immun 2012;80:2121-2132. 